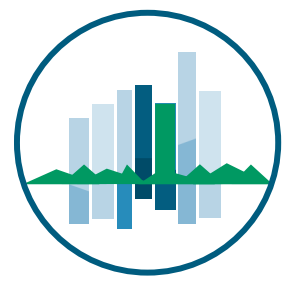

True Smart and Green City?

8th Conference of the

International Forum on Urbanism
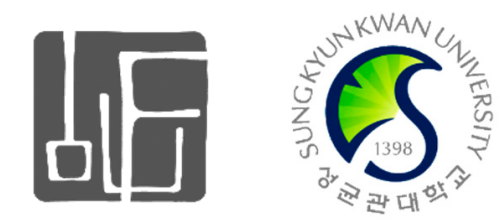

Conference Proceedings Paper

\title{
Assessment of Green Space Spatial Equity in Singapore's Urbanity
}

\author{
Rosita Samsudin * and Puay Yok Tan \\ Department of Architecture, National University of Singapore, 4 Architecture Drive, Singapore \\ 117566
}

* Author to whom correspondence should be addressed; Tel.: +65-6601-5014; Fax: +65-6779-3078; E-mail: akirosi@nus.edu.sg

\begin{abstract}
The "Garden City" concept has been driving Singapore's urban development since the 1960s. This has led to the city-state becoming a remarkably green city despite it being also a country with one of the highest population density in the world. A key component in the greening Singapore is the provision of parks as essential living spaces, a process which is driven by national park provision targets. While the targets set are commendable, we suggest that it is also necessary to consider the availability of parks to residents of different sociodemographic and socio-economic profiles, i.e., provision of parks where needs are the strongest. This is currently an unknown area in park planning of Singapore and falls within the emerging area of spatial equity, which has traditionally focused on "environmental bads" but which is now increasingly applied to "environmental goods". In this study, we examined spatial equity of parks as public goods through a spatial study of parks distribution and correlations with key socio-demographic and economic profiles (population, population density, types of home ownership, age groups, and income) of planning units at two spatial scales. The effects of spatial scales on park planning provision indicators were clearly manifested in the study, and we also report on the apparent unequal distribution of parks in Singapore when this was considered against the socio-demographic and socio-economic profiles of residential areas.
\end{abstract}

Keywords: spatial equity; park planning; park provision; urbanization. 